\title{
Thinking About Restoration
}

\section{Some ideas on why too few people do}

One purpose of Restoration \& Management Notes is to help explore, articulate, and in a sense even to publicize the idea that ecological restoration represents a distinctive, and apparently in some ways quite new kind of environmental technology, and therefore an important development in the relationship between human beings and their environment.

This being the case, we pay quite a bit of attention to what people are thinking and saying about restoration, and to who is thinking and saying it. And in general it is our impression that a lot of people don't think about it much at all. Restoration, somehow, has simply not become a conspicuous part either of the modern conservation movement that came out of the 1930 s or of the environmental movement that has taken shape during the last ten or fifteen years.

In particular, environmentalists and academic ecologists, two groups whose interest will ultimately be crucial to the development of restoration as a progressive, effective discipline, have tended to ignore it. There are notable exceptions of course; a considerable number of individuals are involved in restoration in one way or another - some of them passionately. But by and large, the interest of these groups has been tepid at best. The numbers may be considerable, but the percentages are small. A restoration movement based on the idea of restoring communities as a crucial component of our program for environmental management has yet to reach critical mass. California writer John Berger, who is currently writing a book on restoration, has called this technology "the nation's least understood, least publicized ... approach to the gravest environmental and resource management problems affecting the U.S. today."

To the extent this is true, it is worth asking why. Here we can only speculate, but a number of possibilities suggest themselves.

The first, and to us the most obvious, is that there is something unsettling about the idea of restoration, and a general feeling that there is something kind of tacky about a restored community. The reasons for this are obvious. To a considerable extent people value undisturbed nature precisely because, being undisturbed (meaning, of course, by people) it stands for things just as they are-a kind of benchmark for a world without human beings. There is a sense that God made it that way, as Tom Bonnicksen says (page 13), and that sense is naturally diminished by the realization that, say, the CCC had a hand in it as well.

At the same time, the idea of restoration as a desirable - and practical - form of environmental technology might conflict with the traditional environmentalist agenda in other, more practical ways. For one thing, the idea that ecosystems are restorable might be seen as conflicting with the ideas that they are fragile and irreplaceable, which have always been prominent in environmentalist rhetoric. Indeed, the environmental movement has tended to be strongly preservationist in tone, and to the extent that the argument for preservation depends on fragility and irreplaceability, the very idea of restoration might be regarded as a potentially dangerous one, tending to undermine arguments for preservation, and perhaps best left more or less in the background.

Finally, for those environmentalists who are also ecologists, restoration has perhaps remained unattractive as a research pursuit for at least two, somewhat conflicting reasons. On the one hand there is, as Bonnicksen points out, the sheer complexity of the problem, which makes rigorous basic research extremely difficult. On the other, as John Cairns has pointed out (R\&MN I:1,6), restoration as a form of technology carries the stigma of practicality, of "applied" science. In addition to which, as Cairns also points out, restoration implies working with communities that have been disturbed in some way and so feel somehow less "real" than undisturbed, pristine communities.

Whatever the reasons, ecologists have tended to ignore the challenges - and the opportunities - of restoration, and restoration research has tended to be carried out under the auspices of organizations such as the Department of Energy, the Army Corps of Engineers, and the mining industry, which is mildly ironic, since these have traditionally been cast on "the other side" in debates over environmental issues.

There is obviously something healthy about this wider interest. For one thing it suggests that the most recent wave of environmentalism has actually had influence outside the immediate circle of "environmentalists." Yet at the same time, it is clear that both environmentalists (meaning those who place a high value on the natural environment more or less for its own sake) and ecologists have a great deal to contribute to the restoration movement. For it is to environmentalists that restorationists will have to look for moral and political support. And it is the ecologists who will help provide intellectual rigor, coherence, and crucial connections with other disciplines. As Anthony Bradshaw, the president of the British Ecological Society, recently wrote, "Perhaps the crucial point is that the work has to be done, and if ecologists pay no attention, the work will fall into the hands of other professions. Then not only will we have lost all sorts of opportunities to practice the science of ecology but it is also unlikely that the work will be done as well as it should be" (J. of Applied Ecology [1983] 20:1).

And if this is true for ecologists, it is equally true for environmentalists. In practice restoration or reclamation can take many forms, and as these technologies become increasingly important as a way of dealing with the environment, it will become increasingly important that environmentalists as well as ecologists exert themselves to see that they are developed and applied in ecologically sophisticated and environmentally sensitive ways. 